\title{
Anterior Cranial Fossa Meningioma
}

National Cancer Institute

\section{Source}

National Cancer Institute. Anterior Cranial Fossa Meningioma. NCI Thesaurus. Code C5286.

A mening ioma that affects the anterior cranial fossa. 